\title{
VALORES E ENTRINCHEIRAMENTO ORGANIZACIONAL: UM ESTUDO EM UMA SEGURADORA
}

Values and Entrenchment Organizational training: a study in an insurance company

\author{
Ana Paula Timbó Formiga \\ E-mail: paulinha_06@hotmail.com \\ Bacharel em Administração pela Universidade Federal do Ceará. \\ https://orcid.org/0000-0001-5811-8181
}

Luis Eduardo Brandão Paiva
E-mail: edubrandas@gmail.com Mestre em Administração e Controladoria pela Universidade Federal do Ceará; Doutorando em Administração e Controladoria pela Universidade Federal do Ceará; Bolsista na Faculdade de Economia Administração, Atuária, Contabilidade e Secretariado e Executivo da Universidade Federal do Ceará. Endereço para contato: Avenida da Universidade, 2486, Benfica, 60020-180, Fortaleza, Ceará, Brasil. https://orcid.org/0000-0002-5036-6823

\section{Tereza Cristina Batista de Lima}

E-mail: tcblima@uol.com.br Doutora em Educação pela Universidade Federal do Ceará; Mestre em Psicologia (Psicologia Clínica) pela Pontifícia Universidade Católica de São Paulo; Professora no Programa de Pósgraduação em Administração e Controladoria da Universidade Federal do Ceará. https://orcid.org/0000-0002-6594-4921

\section{Serafim Firmo de Souza Ferraz}

E-mail: sfsf@uol.com.br

Doutor em Administração de Empresas pela Fundação Getúlio Vargas de São Paulo; Mestre em Gestion Des Ressources Humaines pela Conservatoire National des Arts et Métiers (CNAM), França; Professor no Programa de Pósgraduação em Administração e Controladoria da Universidade Federal do Ceará. https://orcid.org/0000-0002-7849-4632

Artigo recebido em 19 de maio de 2018. Aceito em 26 de novembro de 2018. 


\section{Resumo}

Neste estudo analisa-se a relação entre os valores no trabalho e o entrincheiramento organizacional, baseando-se nos modelos teóricos de Porto e Pilati (2010), para os valores relativos ao trabalho; e de Rodrigues e Bastos (2012), no tocante ao Entrincheiramento Organizacional. Diante disso, trata-se de uma investigação de natureza quantitativa e descritiva, com base em uma amostra de 102 funcionários de uma seguradora. Os resultados apontaram: as principais recompensas desejáveis no trabalho foram a segurança em poder se sustentar financeiramente e a realização em ser bem-sucedido; e a hierarquia de valores seguiu na seguinte ordem: segurança, realização, conformidade, universalismo/benevolência, autodeterminação/estimulação e poder. Quanto ao Entrincheiramento Organizacional, predominou a percepção das perdas de benefícios pelo indivíduo ao sair da instituição, verificando-se uma relação moderada com a segurança e a estabilidade financeira. De modo geral, os resultados contribuem para suplantar a lacuna da literatura que alinha os valores no trabalho e o Entrincheiramento Organizacional, incentivando o desenvolvimento de pesquisas no campo do comportamento organizacional para os funcionários de seguradoras, por se tratar de uma categoria que sofre, constantemente, com as mudanças no mercado de trabalho.

Palavras-chave: Carreira. Entrincheiramento. Seguradora. Trabalho. Valores.

\section{Abstract}

This study analyzes the relationship between values at work and organizational entrenchment, based on the theoretical models of Porto and Pilati (2010), for the values related to work; and Rodrigues and Bastos (2012), regarding Organizational Entrenchment. In the light of this, it is a quantitative and descriptive investigation, based on a sample of 102 employees of an insurer. The results allowed to point out: the main desirable rewards in the work were the security in being able to be supported financially and the accomplishment in being successful; and the hierarchy of values followed in the following order: security, achievement, conformity, universalism/benevolence, self-determination/ stimulation, and power. As for Organizational Entrenchment, the perception of the loss of benefits by the individual when leaving the institution prevailed, with a moderate relationship with security and financial stability. In general, the results contribute to overcome the literature gap that aligns work values and Organizational Entrenchment, encouraging the development of research in the field of organizational behavior for insurance employees, because it is a category that is constantly suffering, with the changes in the labor market.

Keywords: Career. Entrenchment. Insurance company. Job. Values.

\section{INTRODUÇÃO}

Os valores pessoais revelam a disposição do indivíduo em atender a interesses coletivos e/ou individuais (Parks-Leduc, Feldman, \& Bardi, 2015; Porto \& Tamayo, 2008), bem como podem ser uma perspectiva de entendimento das inclinações individuais para terem um vínculo mais próximo com a carreira (Maurer, Hartnell, \& Lippstreu, 2017) e com a organização (Blustein, 2013).

O trabalho constitui-se como um meio para o que o indivíduo possa atingir suas metas pessoais, sendo também um dos elementos centrais da sua identidade social (Caprara et al., 2017). Os valores no trabalho influenciam a relação das pessoas com as organizações em que 
atuam (Parks-Leduc et al., 2015; Porto \& Tamayo, 2008), refletindo, ainda, no comprometimento com a empresa (Cohen \& Shamai, 2010; Paiva \& Dutra, 2017; Ribeiro \& Honório, 2014), assim como no desenvolvimento de ações que possibilitem alinhar os valores individuais aos organizacionais (Campos, Lehnhart, Fossá, \& Balsan, 2017).

A situação de trabalhadores que permanecem em uma área de trabalho ou emprego por receio de perdas materiais, custos emocionais e/ou por dificuldades percebidas para encontrar alternativas de trabalho se denomina entrincheiramento (Carson, Carson, \& Bedeian, 1995). O indivíduo entrincheirado encontra-se em uma posição fixa e defensiva, conforme se sugere o próprio significado da palavra (Macambira, Bastos, \& Rossoni, 2015), com uma carreira entrincheirada (Carson, 1996) que dificulta mudanças e faz com que o indivíduo se sinta preso na organização (Zacher, Ambiel, \& Noronha, 2015).

Esse processo tem sido investigado em relação à carreira (Magalhães \& Gomes, 2007; Zacher et al., 2015) e à organização (Carvalho, Alves, Peixoto, \& Bastos, 2011), como a expressão de uma base psicológica instrumental de vínculo. O conceito de Entrincheiramento Organizacional (EO) surge com a necessidade de investigar fatores que, até então, eram considerados parte do comprometimento e, diante disso, busca-se aumentar a precisão conceitual e empírica dos constructos que compõem os vínculos do indivíduo com a organização (Rodrigues \& Bastos, 2012). Tal conceito segmenta-se em três dimensões, consoante Rodrigues (2009): Ajustamentos à Posição Social (APS), Arranjos Burocráticos Impessoais (ABI) e Limitação de Alternativas (LA) - utilizadas nesta pesquisa empírica.

Observa-se, nas últimas décadas, o crescimento de pesquisas sobre as atitudes de funcionários relacionadas ao trabalho, bem como sobre a relação com o comprometimento no trabalho (Cohen \& Shamai, 2010), sobretudo se levando em conta o Entrincheiramento Organizacional (Almeida, Azevedo, \& Aquino, 2017; Menezes, Paiva, \& Lima, 2018; Zacher et al., 2015) de funcionários que trabalham com as constantes mudanças do mercado de trabalho. Nessa perspectiva, formula-se a seguinte questão norteadora: qual a relação entre valores no trabalho e o Entrincheiramento Organizacional?

No estudo teve-se como objetivo geral analisar a relação entre os valores no trabalho e o Entrincheiramento Organizacional. Nesse contexto, delimitaram-se como objetivos específicos: identificar a hierarquia dos valores relativos ao trabalho; verificar o nível de Entrincheiramento Organizacional; e relacionar as dimensões dos valores no trabalho e do Entrincheiramento Organizacional.

Esta investigação tomou como base os funcionários de uma seguradora, por se tratar de uma categoria que sofre, constantemente, as mudanças ocorrentes no mundo do trabalho, também por apresentarem impactos diretos no desenvolvimento econômico do País. No Brasil são escassos os estudos que versam sobre a relação entre os valores e o comprometimento organizacional (Fernandes \& Ferreira, 2009), principalmente enfatizando o Entrincheiramento Organizacional. As relações entre os valores no trabalho e os vínculos com a carreira também ainda são pouco 
exploradas na literatura empírica e conceitual sobre os temas (Cohen, 1999; Zacher et al., 2015; Wilson, Liddell, Hirschy, \& Pasquesi, 2016).

Destarte, neste estudo busca-se suplantar essa lacuna da literatura, alinhando os valores no trabalho e o Entrincheiramento Organizacional dos funcionários de uma seguradora, a fim de contribuir para o campo do conhecimento voltado para a gestão estratégica de pessoas (Freire, 2015), no âmbito das seguradoras. Logo, espera-se que o resultado venha a fornecer um instrumento de diagnóstico para gestores da área de seguros, possibilitando, então, identificar os valores e o Entrincheiramento Organizacional.

\section{VALORES NO TRABALHO}

Schneider (1917) foi o primeiro pesquisador a propor o relacionamento entre os tipos de valores. Foram criados, nos anos 1970, instrumentos de pesquisas voltados para os valores, sido amplamente testados e aceitos em diversas investigações, contando com o pioneirismo de Rokeach (1973). Entre os anos 1960 e 1970, Rokeach (1973) dedicou-se ao estudo dos valores, sendo o seu foco principal a definição e o entendimento dos valores individuais; em seguida, destacam-se Meglino e Ravlin (1998), Schwartz et al. (2012), Dens, Pelsmacker e Meulenaer (2017) e Schwartz (2017).

Schwartz (1992, 1994), por sua vez, é considerado o principal pesquisador dos valores humanos, ditando os valores como metas que operam como princípios, e que, consequentemente, orientam a vida das pessoas. Por sua vez, Schwartz (1992, 1994, 2017) destaca a Teoria de Valores, definida mediante 10 tipos motivacionais, os quais são reconhecidos entre as diversas culturas do mundo.

Os 10 tipos motivacionais de valores, propostos por Schwartz $(1992,1994,2017)$ são: autodeterminação (independência de pensamento e de ação); estimulação (novidade e desafio na vida); hedonismo (prazer individual associado essencialmente aos sentidos); realização (êxito pessoal baseado na demonstração de competência); poder (status social, domínio e controle sobre pessoas e recursos); segurança (harmonia e estabilidade da sociedade, das relações e de si mesmo); conformidade (conduta alinhada com normas sociais e códigos coletivos); tradição (respeito e aceitação dos costumes e ideias culturalmente estabelecidos); benevolência (preservação e fortalecimento do bem-estar dos que estão próximos); e universalismo (apreço pelo bem comum e proteção da natureza).

Cada um dos valores representa, por sua vez, uma meta ou motivação, contendo elementos materiais (consequências práticas), afetivos (sentimentos em geral) ou cognitivos (opiniões, crenças e considerações) que expressam interesses individualistas, coletivistas ou mistos (Dens, Pelsmacker, \& Meulenaer, 2017; Elizur \& Sagie, 1999; Parks-Leduc et al., 2015).

Schwartz (1992) desenvolveu uma escala que busca explicar a estrutura dinâmica das relações entre os valores. Com o estudo dessa estrutura, foi identificado de que forma as ações na busca de um valor produzem consequências de sinergia ou conflito com a busca de outros valores. No modelo representado na Figura 1, os valores são representados em um círculo, formando um continuum de motivações que se relacionam com os valores adjacentes. 


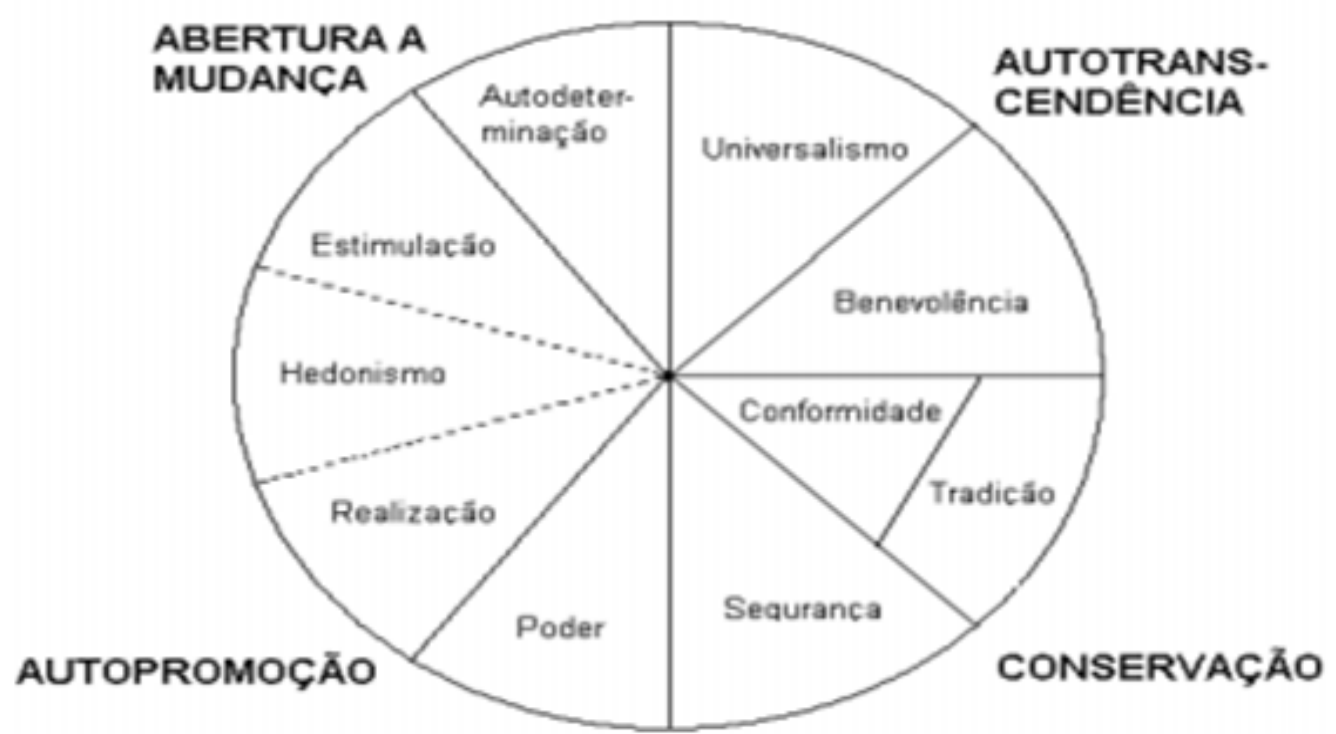

Figura 1. Estrutura teórica da relação entre valores. Adaptada de "Universales in content and structure of values: Theorical advances and empirical testes in 20 countries," by S. H. Schwartz, 1992, Advances in Experimental Social Psychology, 25, 1-65.

Verificam-se duas dimensões, consideradas bipolares: a primeira reflete a busca de mudança em oposição à estabilidade, expressando a motivação da pessoa para seguir os seus próprios interesses intelectuais e afetivos, desafiando a preservação de um estado de segurança de seus relacionamentos; no extremo, estão os tipos motivacionais de estimulação e autodeterminação, com valores ligados à inovação, criação, autonomia e abertura a desafios nas várias áreas da vida. No outro extremo dessa dimensão se encontram os tipos motivacionais de segurança, conformidade e tradição, nos quais os indivíduos têm motivação na busca de estabilidade, segurança, ordem social, autocontrole e respeito à tradição.

A segunda dimensão polariza, de um lado, a autotranscedência em oposição à autopromoção, determinando extremos entre a busca dos interesses próprios (ego centrado) e os interesses dos outros (outro centrado). Em um dos extremos estão os tipos motivacionais universalismo e benevolência, determinados por valores voltados aos resultados coletivos do grupo e da organização, promovendo o bem-estar dos outros. No outro polo a ênfase é com os seus próprios resultados, sem preocupação com os resultados coletivos, em que os valores evidenciados são poder e influência. A teoria dos valores humanos, proposta por Schwartz (1992), tem recebido a atenção de diversos pesquisadores que procuram entender relações entre valores, atitudes e comportamentos no trabalho (Caprara et al., 2017; Parks-Leduc et al., 2015; Schwartz et al., 2012; Schwartz, 2017).

Os valores no trabalho são componentes considerados essenciais para explicar a realidade social que influencia o tipo de trabalho desenhado às pessoas, a socialização para o trabalho e a forma como elas relacionam o trabalho a outros aspectos da sua vida (Caprara et al., 2017; Oliveira, El-Aouar, De Vasconcelos, \& Gurgel, 2016; Tamayo \& Porto, 2003). 
De modo geral, o trabalho é considerado fundamental na constituição da identidade social de um indivíduo, pois é nesse ambiente que ele passa boa parte de sua vida, buscando realizar metas e objetivos de vida (Caprara et al., 2017; Porto \& Tamayo, 2008). Os valores no trabalho são referidos ao estado de existência desejado pelas pessoas, que, consequentemente, podem ser alcançados por meio dos resultados no trabalho, considerados os princípios que guiam a vida delas nas organizações (Merlo \& Mendes, 2009; Nord, Brief, Atieh, \& Doherty, 1988; Schwartz et al., 2012; Parks-Leduc et al., 2015; Schwartz, 2017; Tamayo, Mendes, \& Paz, 2000).

\section{ENTRINCHEIRAMENTO ORGANIZACIONAL}

O entrincheiramento foi abordado, primeiramente, no artigo publicado por Carson et al. (1995) e Carson et al. (1996), em que tiveram como foco principal a carreira do indivíduo. Por que o foco em carreira e não na organização, como até então vinha sendo estudado o comprometimento? O entrincheiramento é uma metáfora que remete à continuidade de profissionais em uma carreira, porque mudar Ihes parece desvantajoso ou inviável. Ficam, assim, protegidos em sua trincheira - a carreira, nomeada de "carreira entrincheirada" (Zacher et al., 2015; Wilson et al., 2016).

Levando-se em conta a perspectiva de Carson et al. (1995), Carson et al. (1996), Rodrigues e Bastos (2012) e Zacher, Ambiel e Noronha (2015), o entrincheiramento é um processo de estagnação no qual os indivíduos não se adaptam e não se motivam a encontrar alternativas para seu encaminhamento profissional. Alguns sintomas do entrincheiramento podem ser: medo de estigma social, visão da idade como fator de limitação das alternativas de carreira e percepção de desequilíbrio na relação custo-benefício da mudança.

A carreira adquiriu maior relevância na vida profissional dos indivíduos (Zacher et al., 2015). Por sua vez, Taylor e Giannantonio (1993) asseguram que se torna importante examinar as implicações práticas dessa forma de ligação com a carreira, tanto no nível dos indivíduos quanto das organizações, até mesmo porque o indivíduo entrincheirado pode estar resignado com a sua situação por reconhecer a falta de alternativas, mas outro pode estar insatisfeito com a situação e desejar mudar, ainda que seja para realizar outras atividades que o permitam se desenvolver pessoalmente e profissionalmente.

O conceito de entrincheiramento na carreira não é definido puramente por meio de dimensões psicológicas, mas por abordagens associadas à perspectiva de continuação nas quais os indivíduos permanecem em uma ocupação, por causa de recompensas externas associadas com a carreira e perdas que seriam incorridas caso eles desistissem dela (Carson et al., 1995; Carson et al., 1996).

O conceito para entrincheiramento na carreira, proposto por Carson et al. (1995) é constituído por três componentes: investimento na carreira - investimentos acumulados em uma carreira de sucesso e que seriam perdidos ou que valeriam menos caso fosse buscada uma nova carreira; custos emocionais - custos emocionais associados com a atuação em uma nova carreira; 
e alternativas de carreira limitadas - percepção da ausência de opções disponíveis para o exercício de uma nova carreira.

O fator investimento na carreira guarda forte associação com o conceito de side-bets, proposto por Becker (1960). Já os custos emocionais estão relacionados às perdas das relações interpessoais associadas à mudança de carreira. A limitação de alternativas de carreiras ocorre, por exemplo, porque quanto mais tempo o profissional passa em uma carreira, mais os seus conhecimentos acabam ficando muito especializados, reduzindo, assim, as opções de outras carreiras nas quais esse conhecimento específico pode igualmente ser aproveitado. Como sugerido por Carson et al. (1995), o conceito de entrincheiramento se aplica tanto no nível do indivíduo quanto no nível da organização. Porém, Carson e Carson (1997) apresentam o conceito de entrincheiramento como uma das fases do comprometimento.

Rodrigues (2009) propôs a aplicação do conceito do entrincheiramento no âmbito da organização e, com isso, o conceito do Entrincheiramento Organizacional pode ser definido como a tendência de um indivíduo a permanecer em razão de possíveis perdas de investimentos e de custos associados à sua saída, e também da percepção de poucas alternativas fora daquela organização. Em suma, esse conceito visa mensurar o quanto o empregado se sente "preso" à organização por necessidade.

Esse conceito apresenta três dimensões: ajustamentos à posição social (APS), que representam os investimentos feitos pelos indivíduos nas condições necessárias à sua adaptação ao trabalho, a exemplo dos treinamentos feitos e dos vínculos afetivos estabelecidos com os colegas; arranjos burocráticos impessoais (ABI), que estão associados aos benefícios que seriam perdidos caso o empregado saísse da organização, a exemplo de férias, assistência médica, estabilidade; e limitação de alternativas (LA), percepção sobre a existência de poucas alternativas, caso saísse da organização, seja por uma restrição do próprio mercado de trabalho, por sua qualificação, seja mesmo por questões associadas à idade (Carson \& Carson, 1997; Rodrigues, 2009; Rodrigues \& Bastos, 2012). 


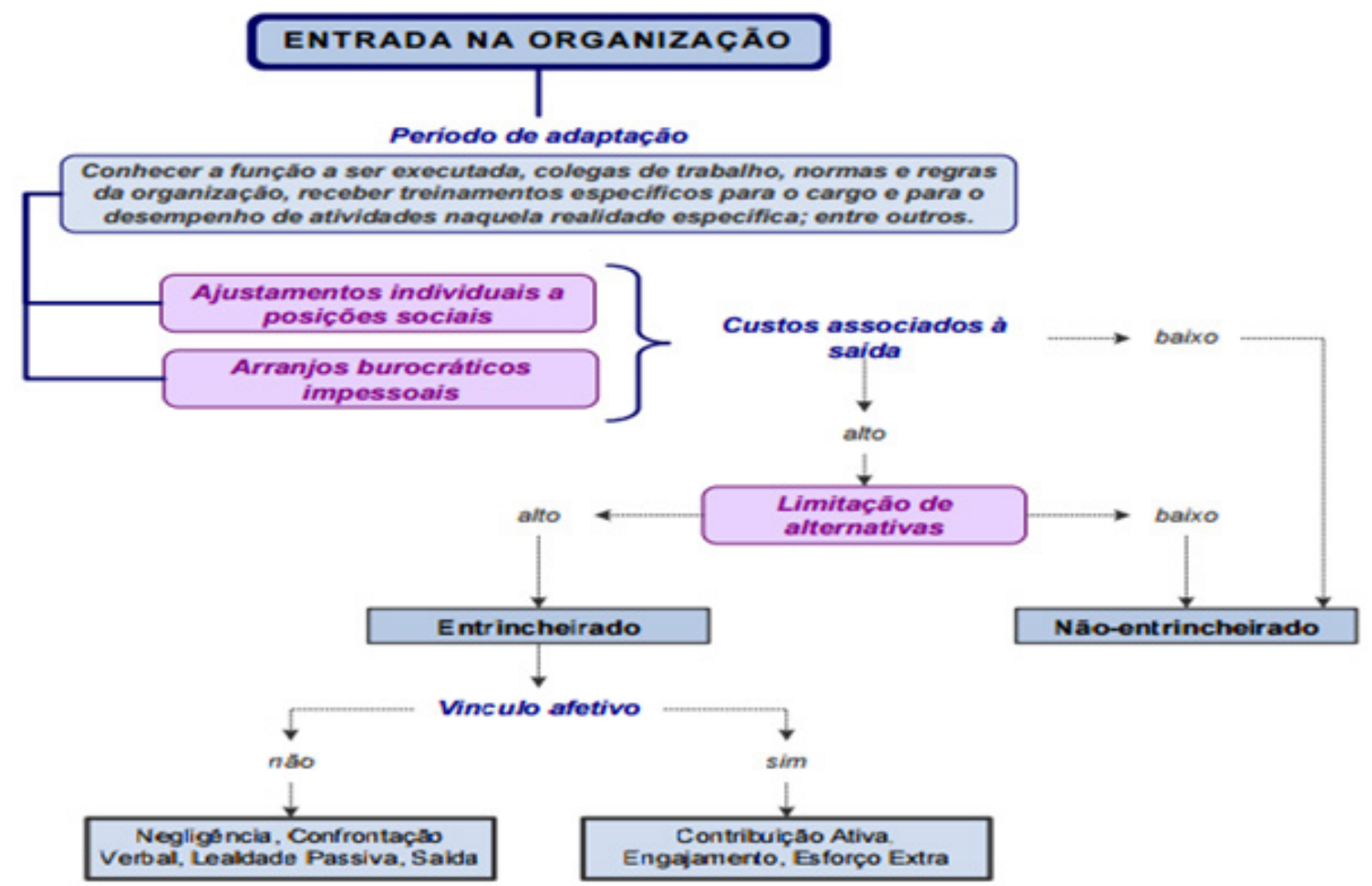

Figura 2. Modelo de entrincheiramento na organização. Adaptada de "Career entrenchment: A quiet march toward occupational dealth?," by K. D. Carson and P. P. Carson, 1997, The Academy of Management Executive, 11 (1), 62-75.

De acordo com Carson et al. (1995), os sintomas de entrincheiramento podem levar ao desejo de evitar o estigma social, associado à retirada da carreira; aos temores de que a idade e habilidades específicas possam limitar sua empregabilidade; a uma relutância em abandonar o status adquirido em sua profissão; e ao ceticismo sobre o futuro potencial de ganho. Rodrigues (2009) e Zacher, Ambiel e Noronha (2015) salientam que é possível que indivíduos entrincheirados, presos às suas carreiras por necessidade, não estejam preocupados com sua produtividade nem engajados na possibilidade de contribuir para futuras gerações.

Profissionais entrincheirados podem ter tendências de resistir a mudanças e à permanência na estabilidade. Eles permanecem na organização não porque desejam, mas por medo de perderem benefícios oferecidos por ela, caso o vínculo se desfaça (Rodrigues \& Bastos, 2012). Se profissionais entrincheirados estão satisfeitos com a sua situação, pode não haver consequências disfuncionais associadas para indivíduos e/ou suas organizações. Sem alternativa a não ser ficarem desempregados, esses empregados podem fazer as pazes com sua própria carreira enraizada. Outros podem mudar de função para que colegas possam ajudá-los a continuar seu desenvolvimento pessoal e profissional. Alternativamente, aqueles cujas perspectivas de progresso são indesejavelmente corroídas pelo entrincheiramento de carreira, podem vir a ser apenas passivos organizacionais (Carson et al., 1995; Carson \& Carson, 1997).

Baiocchi e Magalhães (2004) concluíram que o indivíduo que tem alta identificação com sua carreira tende a entrincheirar-se em decorrência dos receios de ameaça à sua identidade 
profissional em caso de mudança. Magalhães e Gomes (2007) incluíram o comprometimento com a carreira, o entrincheiramento e a generatividade (envolvimento do indivíduo com o bem-estar das próximas gerações), em que o entrincheiramento obteve relação negativa com a generatividade, enquanto que o comprometimento apresentou relação positiva com essa variável (generatividade).

Rowe, Bastos, e Pinho (2011), por sua vez, evidenciaram que o comprometimento com a carreira leva a um maior desempenho; e quanto ao entrincheiramento, este mostrou que os investimentos na carreira detêm influência positiva no esforço instrucional, isto é, quanto mais o docente investe dinheiro e tempo à capacitação, aumenta-se o sev esforço instrucional. Macambira et al. (2015) reforçam que o entrincheiramento se refere a uma relação decorrente de uma avaliação calculativa, dado que os custos de saída da organização, bem como as alternativas, são elevados para o indivíduo.

De modo geral, pesquisas que versam sobre o entrincheiramento estão o alinhando com outros constructos, como comprometimento de continuação (Rodrigues \& Bastos, 2012; Scheible \& Bastos, 2006), percepção sobre práticas de gestão de recursos humanos (Scheible \& Bastos, 2013), satisfação no trabalho (Carson et al., 1996) e consentimento e comprometimento (Almeida et al., 2017; Macambira et al., 2015).

Dessa forma, Rodrigues e Bastos (2012) sugerem, então, estudos que investiguem o entrincheiramento organizacional em diferentes segmentos e públicos. Logo, este estudo está nesse contexto com o intuito de analisar a relação entre os valores no trabalho e o Entrincheiramento Organizacional, baseando-se nos funcionários de uma seguradora.

\section{METODOLOGIA}

Considera-se a classificação proposta para este estudo por Collis e Hussey (2005), tratandose de uma pesquisa natureza quantitativa e descritiva, que busca descrever o Entrincheiramento Organizacional e os valores no trabalho de modo a compreender quais os motivos que limitam a tentativa de mudar de ramo/organização quando o indivíduo está desmotivado ou cansado da atividade atual.

A partir de uma pesquisa survey intencional, por meio de uma amostra não probabilística, foram obtidos dados primários, isto é, originais e inéditos junto aos funcionários de uma seguradora, localizada na Cidade de Fortaleza, Ceará, Brasil. Essa empresa de seguros, de âmbito nacional, foi fundada em 2004, atuando no ramo de automóveis, detém uma carteira de mais de 1,4 milhão de veículos cobertos e mais de 1,5 milhão de residências seguradas, com cerca de 140 funcionários na filial de Fortaleza, cuja matriz fica na Cidade do Rio de Janeiro.

Dentro do universo de pesquisa foi obtida uma amostra de 102 funcionários da área Administrativa e Comercial, considerando um nível de confiança de $99 \%$ e margem de erro de 10\%, fato que indica o valor satisfatório, tendo em vista que a amostra mínima exigida - corrigida pelo tamanho da população - é de 98 indivíduos. Assim, a amostra é significante para representar a população investigada. 
Destarte, para a coleta de dados foi utilizado um questionário estruturado, composto por questões relacionadas ao perfil sociodemográfico e duas escalas previamente validadas na literatura (estruturadas por meio de uma escala likert de cinco pontos, variando na primeira escala entre discordo totalmente e concordo totalmente; e na segunda escala entre nada importante e extremamente importante), uma vez que a investigação ocorreu de forma presencial pelos pesquisadores, entre maio e julho de 2017.

A primeira escala - Escala Revisada de Valores Relativos ao Trabalho (EVT-R), de Porto e Pilati (2010), foi dividida em seis fatores: universalismo/benevolência, que denota preocupação com questões sociais e humanitárias; poder, que ilustra uma valorização por aspectos ligados ao poder e supervisão; conformidade, que sinaliza um apreço por aspectos normativos e de hierarquia bem definidos; autodeterminação/estimulação, composto por itens que denotam a ideia de inovação e autonomia no trabalho; realização, que significa ser admirado e reconhecido pelas atividades desempenhadas no trabalho; e segurança, que representa aspectos de sucesso e estabilidade financeira.

A segunda escala foi a versão reduzida da Escala de Entrincheiramento Organizacional (EEO), proposta por Rodrigues e Bastos (2012), distribuída em três dimensões: Ajustamentos à Posição Social (APS), que se referem aos investimentos feitos para a adaptação à posição em que o indivíduo se encontra e às condições necessárias para o bom desempenho, os quais serão perdidos em caso de saída; a segunda dimensão, Arranjos Burocráticos Impessoais (ABI), está associada a ganhos materiais, estabilidade financeira e funcional e benefícios perdidos com a saída; e, por último, a dimensão Limitação de Alternativas (LA), que se refere à percepção de restrições de empregabilidade, fazendo com que o indivíduo se sinta preso.

Para o tratamento dos dados foram utilizados estatística descritiva e inferencial, com o uso do mínimo, máximo, média e desvio padrão; Alfa de Cronbach, que mensura a consistência interna dos itens; e análise multivariada dos dados, por meio da correlação de Pearson, que mensura o grau de relação linear entre duas variáveis quantitativas, variando de -1 a 1 (Hair, Black, Babin, Anderson, \& Tatham, 2009). As análises estatísticas das respostas foram feitas por meio do software Statistical Package for the Social Sciences (SPSS) (versão 22.0).

\section{ANÁLISE E DISCUSSÃO DOS RESULTADOS}

\subsection{PERFIL DA AMOSTRA}

Entre o total de respondentes, $58,8 \%$ são mulheres e $41,2 \%$ são homens, o que mostra um cenário com mais mulheres do que homens no ambiente de trabalho. A idade média concentrouse entre 26 e 35 anos, para ambos os sexos. Na perspectiva de Bruschini (2000), a participação da mulher no mercado de trabalho aumentou de forma significativa a partir da década de 1990, e então seu espaço foi sendo conquistado, cada vez mais, nas diversas áreas e posições hierárquicas, ampliando-se no século XXI (Perez, 2017) sobretudo por meio de seus valores e expectativas no trabalho (Brandão, Ferraz, \& Lima, 2015). 
O tempo de serviço com maior ênfase foi de um a três anos, com $37 \%$ dos indivíduos, e isso demonstra que o perfil da empresa se concentra em funcionários que entraram recentemente. A concentração de pessoas com mais de 10 anos na empresa se restringiu a apenas $10 \%$ do total, apontando que a empresa apresenta alta rotatividade.

No tocante à escolaridade, 10 indivíduos têm o ensino médio completo, 30 estão cursando graduação, 39 com diploma de ensino superior completo e 23 pós-graduados. Nessa análise, percebe-se que mais da metade dos funcionários $(60,7 \%)$ têm graduação completa. Quanto ao estado civil, $51 \%$ são casados, $4 \%$ estão em uma união estável e $45 \%$ são solteiros.

Em relação à responsabilidade financeira, a maioria respondeu que divide os custos domésticos igualmente com os demais dentro de casa, ou seja, 38\% dos respondentes, os demais se concentraram em $29 \%$, os quais contribuem com uma pequena parte; $20 \%$ se enquadram como 0 principal responsável financeiro, 10\% como o único responsável; e apenas $3 \%$ informaram que não têm nenhuma responsabilidade financeira. Portanto, o cenário demonstra que os funcionários, em sua maioria, não são os únicos responsáveis no âmbito financeiro, o que pode facilitar uma eventual busca por outras empresas.

No que tange à distribuição salarial, há predominância da faixa de um a dois salários mínimos (de $\mathrm{R} \$ 937,00$ a 1.874,00) para 49\% da amostra. Uma média salarial baixa para o mercado de Administração, pois o Conselho Federal de Administração (CFA) sugere o salário de $R \$ 2.458,00$ para quem inicia na carreira e pelo menos de $R \$ 5.977,00$ para profissionais com mais de dois anos de experiência.

\subsection{ANÁLISE DOS VALORES NO TRABALHO}

Considerando o primeiro objetivo específico identificar a hierarquia dos valores relativos ao trabalho", apresentam-se os resultados dos itens e sua representatividade na mensuração de cada fator. Foram abordados os 34 itens, agrupados de acordo com os seguintes tipos motivacionais: autodeterminação/estimulação (AE), segurança (SE), realização (RE), poder (PO), conformidade (CO), universalismo/benevolência (UB), baseados em Schwartz (1992) e Porto e Pilati (2010) (Tabela 1). 
Tabela 1

Estatísticas da escala revisada dos valores relativos ao trabalho (EVT-R)

\begin{tabular}{|c|c|c|c|c|}
\hline & Mínimo & Máximo & Média(M) & Desvio padrão \\
\hline UB1 - Ajudar os outros & 3,00 & 5,00 & 3,8529 & ,91627 \\
\hline UB2 - Colaborar para o desenvolvimento da sociedade & 2,00 & 5,00 & 3,6765 & 99665 \\
\hline UB3 - Combater injustiças sociais & 1,00 & 5,00 & 3,4706 & 1,06897 \\
\hline UB4 - Ser útil para a sociedade & 2,00 & 5,00 & 3,5294 & 91960 \\
\hline UB5 - Ter compromisso social & 2,00 & 5,00 & 3,5588 & 91817 \\
\hline $\begin{array}{l}\text { PO1 - Competir com colegas de trabalho para alcançar as minhas } \\
\text { metas profissionais }\end{array}$ & 1,00 & 5,00 & 2,5000 & 1,06938 \\
\hline PO2 - Supervisionar outras pessoas & 1,00 & 5,00 & 3,1176 & 1,02729 \\
\hline PO3 - Ter fama & 1,00 & 5,00 & 2,5294 & 1,14931 \\
\hline PO4 - Ter prestígio & 1,00 & 5,00 & 2,9412 & 1,06076 \\
\hline PO5 - Ter uma profissão reconhecida socialmente & 2,00 & 5,00 & 3,6765 &, 96638 \\
\hline REl - Demonstrar minhas competências & 3,00 & 5,00 & 4,1765 & ,70937 \\
\hline RE2 - Ser admirado pelo meu trabalho & 2,00 & 5,00 & 4,0294 & 89505 \\
\hline RE3 - Ser bem-sucedido na minha profissão & 3,00 & 5,00 & 4,2353 & ,77302 \\
\hline RE4 - Ser reconhecido pelo resultado satisfatório do meu trabalho & 3,00 & 5,00 & 4,2059 & ,76220 \\
\hline RE5 - Ser respeitado pelas minhas competências no trabalho & 2,00 & 5,00 & 4,1176 & 83600 \\
\hline SE1 - Obter estabilidade financeira & 3,00 & 5,00 & 4,2059 & ,72218 \\
\hline SE2 - Ganhar dinheiro & 3,00 & 5,00 & 4,1471 & ,69506 \\
\hline SE3 - Poder me sustentar financeiramente & 3,00 & 5,00 & 4,3235 & 83443 \\
\hline SE4 - Ser independente financeiramente & 3,00 & 5,00 & 4,2647 & ,74364 \\
\hline SE5 - Ter melhores condições de vida & 1,00 & 5,00 & 3,8235 & 1,12937 \\
\hline CO1 - Obedecer às normas do trabalho & 2,00 & 5,00 & 4,0882 &, 85715 \\
\hline CO2 - Respeitar a hierarquia & 2,00 & 5,00 & 4,0882 & 89113 \\
\hline CO3 - Ter um ambiente de trabalho com hierarquia clara & 1,00 & 5,00 & 3,2353 & 97672 \\
\hline CO4 - Ter um trabalho organizado & 2,00 & 5,00 & 4,0294 & 82601 \\
\hline AEl - Ter autonomia na realização das minhas tarefas & 2,00 & 5,00 & 3,6176 & 94444 \\
\hline AE2 - Ter desafios constantes & 1,00 & 5,00 & 3,5000 & 1,01230 \\
\hline AE3 - Ter liberdade para decidir a forma de realização do meu trabalho & 2,00 & 5,00 & 3,4706 & 85255 \\
\hline AE4 - Ter um trabalho arriscado & 1,00 & 4,00 & 2,0882 & 1,07264 \\
\hline AE5 - Ter um trabalho que me permita expressar meus conhecimentos & 3,00 & 5,00 & 4,0882 & ,70504 \\
\hline AE6 - Ter um trabalho que requer originalidade & 2,00 & 5,00 & 3,7647 & 88078 \\
\hline AE7 - Ter um trabalho criativo & 3,00 & 5,00 & 3,5882 & 69443 \\
\hline AE8 - Ter um trabalho inovador & 2,00 & 5,00 & 3,6176 & 80891 \\
\hline AE9 - Ter um trabalho que me permita conhecer lugares novos & 2,00 & 5,00 & 3,6765 & 86930 \\
\hline AE10 - Ter um trabalho que me permita conhecer pessoas novas & 2,00 & 5,00 & 3,5882 & ,77527 \\
\hline
\end{tabular}

Observou-se, então, que quanto à percepção para a autodeterminação/estimulação (AE), a resposta que teve maior relação de importância foi a AE5 "Ter um trabalho que me permita expressar meus conhecimentos" ( $M=4,08)$; com isso, verifica-se que os indivíduos têm a percepção de que precisam mais liberdade de expor seus conhecimentos para ajudar, de forma positiva, a operação de rotina e, assim, contribuir com os resultados da empresa. Quanto às questões de segurança (SE), o item que obteve maior média foi o SE3 "Poder me sustentar financeiramente" (M = 4,32), visto que para o indivíduo a importância é ser independente financeiramente, de forma que seu sustento Ihe permita a sua satisfação. Essa variável entra em conflito com a questão salarial, pois o salário administrativo para a empresa investigada não é tão atrativo e não gera a percepção 
positiva de independência financeira, conforme evidenciado por Costa e Dutra (2011) e Paiva, Lima e Pitombeira (2017), em investigações sobre a percepção de sucesso na carreira.

No tipo motivacional realização (RE), ocorreu destaque para o item RE3 ( $M=4,23$ ), no qual consta a seguinte informação "Ser bem-sucedido na minha profissão", fato indicativo para inferir que o indivíduo busca, constantemente, no seu esforço profissional, o diferencial e o reconhecimento no que faz. Com relação ao poder (PO), a questão com maior ênfase foi a PO5 "Ter uma profissão reconhecida socialmente" ( $M=3,67)$, possibilitando demonstrar a necessidade de se trabalhar em uma profissão que proporcione satisfação individual, com respeito e admiração da sociedade. Quanto à conformidade, o item $\mathrm{CO} 1$ "Obedecer às normas do trabalho" $(M=4,08)$ demonstra o comprometimento dos colaboradores em respeitar a conduta estabelecida pela empresa em estudo. Para o universalismo (UB), o item com maior relevância foi o UB1 "Ajudar os outros" (M $=3,85$ ), podendo-se ressaltar que funcionário se vê proativo, desempenhando o seu papel com caráter humano, ajudando os outros e possibilitando um ambiente harmonioso (Schwartz et al., 2012; Schwartz, 2017).

Na Tabela 2 evidenciam-se os resultados da média (M), desvio padrão (sd) e Alfa de Cronbach (a) dos tipos motivacionais da EVT-R, podendo-se observar que todos os valores do Alfa de Cronbach foram superiores a 0,70, estimando a confiabilidade interna dos itens.

Tabela 2

Média e desvio padrão da EVT-R

\begin{tabular}{|c|c|c|c|c|}
\hline Tipos motivacionais & N. de itens & Média & Desvio padrão & Alfa de Cronbach \\
\hline Segurança (SE) & 5 & 4,15 & 0,82 & 0,76 \\
\hline Universalismo/benevolência (UB) & 5 & 3,61 & 0,96 & 0,88 \\
\hline Realização (RE) & 5 & 4,15 & 0,79 & 0,90 \\
\hline Conformidade (CO) & 4 & 3,86 & 0,88 & 0,63 \\
\hline Autodeterminação/estimulação (AE) & 10 & 3,52 & 0,91 & 0,68 \\
\hline Poder (PO) & 5 & 2,95 & 1,05 & 0,69 \\
\hline EVT-R & 34 & 3,68 & 0,88 & 0,74 \\
\hline
\end{tabular}

A análise da importância atribuída pelos respondentes aos VRT-R demonstra a seguinte hierarquia: (1) Segurança e Realização ( $M=4,15)$, (2) Conformidade ( $M=3,86)$, (3) Universalismo/ benevolência $(M=3,61)$, (4) Autodeterminação/estimulação $(M=3,52)$ e (5) Poder $(M=2,95)$. Diante disso, verifica-se que os funcionários priorizam a independência financeira, demonstrando que consideram mais importante ganhar dinheiro para alcançar sua estabilidade e serem bem-sucedidos na profissão (Schwartz, 1994; Porto \& Tamayo, 2008). O fato de ter uma profissão reconhecida socialmente, assim como conhecer novos lugares, também foram fatores determinantes para $\circ$ esforço diário em sua rotina, não deixando de ajudar colegas de trabalho. Todavia, a necessidade de expressar seus conhecimentos no ambiente e ter poder foram os itens menos valorizados (Caprara et al., 2017; Porto \& Pilati, 2010). 


\subsection{ANÁLISE DA ESCALA DO ENTRINCHEIRAMENTO}

Pretendendo-se atender ao segundo objetivo específico "verificar o nível de Entrincheiramento Organizacional", foi utilizada a versão reduzida da Escala de Entrincheiramento Organizacional (EEO). A partir desses resultados, identificaram-se os fatores que mais afetam o entrincheiramento dos funcionários na organização. A versão da EEO compõe 18 itens distribuídos, em três dimensões: posição social (APS), arranjos burocráticos impessoais (ABI) e limitações das alternativas (LA). A Tabela 3 mostra os achados da EEO:

Tabela 3

Estatísticas da Escala de Entrincheiramento (EEO)

\begin{tabular}{|c|c|c|c|c|c|}
\hline & $\mathbf{N}$ & Mínimo & Máximo & Média & Desvio padrão \\
\hline $\begin{array}{l}\text { APS } 1 \text { - Se eu fosse trabalhar em outra empresa, estaria jogando fora } \\
\text { todo o esforço que fiz para aprender as tarefas do meu cargo atual. }\end{array}$ & 102 & 1,00 & 5,00 & 1,7941 & 1,18854 \\
\hline $\begin{array}{l}\text { APS2 - Se deixasse essa organização, sentiria como se estivesse des- } \\
\text { perdiçando anos de dedicação. }\end{array}$ & 102 & 1,00 & 5,00 & 1,6176 & 1,11732 \\
\hline $\begin{array}{l}\text { APS3 - Sair dessa organização significaria, para mim, perder parte } \\
\text { importante da minha rede de relacionamentos. }\end{array}$ & 102 & 1,00 & 5,00 & 2,1471 & 1,31554 \\
\hline $\begin{array}{l}\text { APS4 - Se eu fosse trabalhar em outra empresa, jogaria fora todos os } \\
\text { esforços que fiz para chegar onde cheguei dentro dessa empresa. }\end{array}$ & 102 & 1,00 & 5,00 & 2,1176 & 1,41627 \\
\hline $\begin{array}{l}\text { APS5 - Se eu fosse trabalhar em outra empresa, demoraria a conse- } \\
\text { guir ser tão respeitado como sou hoje dentro dessa empresa. }\end{array}$ & 102 & 1,00 & 4,00 & 1,9118 & ,95547 \\
\hline $\begin{array}{l}\text { APS6 - Se eu fosse trabalhar em outra empresa, levaria muito tempo } \\
\text { para me acostumar a uma nova função. }\end{array}$ & 102 & 1,00 & 4,00 & 2,0294 & 1,15575 \\
\hline $\begin{array}{l}\text { LA1 - Eu acho que teria poucas alternativas de emprego se deixasse } \\
\text { essa organização. }\end{array}$ & 102 & 1,00 & 5,00 & 1,8235 & 1,10276 \\
\hline $\begin{array}{l}\text { LA2 - Mantenho-me nessa organização porque sinto que não conse- } \\
\text { guiria facilmente entrar em outra organização. }\end{array}$ & 102 & 1,00 & 5,00 & 1,7059 & 1,13092 \\
\hline $\begin{array}{l}\text { LA3 - Mantenho-me nessa organização porque sinto que tenho pou- } \\
\text { cas oportunidades em outras organizações. }\end{array}$ & 102 & 1,00 & 5,00 & 1,5294 & 98208 \\
\hline $\begin{array}{l}\text { LA4 - Uma das poucas consequências negativas de deixar essa or- } \\
\text { ganização seria a falta de alternativas. }\end{array}$ & 102 & 1,00 & 5,00 & 1,9412 & 1,19258 \\
\hline $\begin{array}{l}\text { LA5 - Meu perfil profissional não favorece minha inserção em outras } \\
\text { organizações. }\end{array}$ & 102 & 1,00 & 5,00 & 1,3529 & ,76621 \\
\hline $\begin{array}{l}\text { LA6 - A especificidade do meu conhecimento dificulta minha inser- } \\
\text { ção em outras organizações. }\end{array}$ & 102 & 1,00 & 5,00 & 1,9412 & 1,37750 \\
\hline $\begin{array}{l}\text { ABII - Sinto que mudar de empresa colocaria em risco a minha esta- } \\
\text { bilidade financeira. }\end{array}$ & 102 & 1,00 & 5,00 & 2,7647 & 1,35834 \\
\hline ABI2 - Sair dessa organização agora resultaria em perdas financeiras. & 102 & 1,00 & 5,00 & 2,8235 & 1,36731 \\
\hline $\begin{array}{l}\text { ABI3 - O que me prende a essa organização são os benefícios finan- } \\
\text { ceiros que ela me proporciona. }\end{array}$ & 102 & 1,00 & 5,00 & 2,9118 & 1,40792 \\
\hline $\begin{array}{l}\text { ABI4 - Não seria fácil encontrar outra organização que me ofereces- } \\
\text { se o mesmo retorno financeiro que essa. }\end{array}$ & 102 & 1,00 & 5,00 & 2,9412 & 1,48139 \\
\hline $\begin{array}{l}\text { ABI5 - Os benefícios que recebo nessa organização seriam perdidos } \\
\text { se eu saísse agora. }\end{array}$ & 102 & 1,00 & 5,00 & 3,5588 & 1,44588 \\
\hline $\begin{array}{l}\text { ABI6 - Se eu fosse trabalhar em outra empresa, deixaria de receber } \\
\text { vários benefícios que essa empresa oferece aos seus empregados } \\
\text { (vale-transporte, convênios médicos, vale-refeição, etc.). }\end{array}$ & 102 & 1,00 & 5,00 & 3,0588 & 1,59717 \\
\hline
\end{tabular}

Para a dimensão de Ajustamento à Posição, enfatiza-se o item APS3 "Sair dessa organização significaria, para mim, perder parte importante da minha rede de relacionamentos", sendo o mais recorrente na percepção dos indivíduos $(M=2,14)$. De fato, o funcionário perderá esse contato com os prestadores externos da organização e com a rede de relacionamento interna, visto que durante 
muito tempo ele se dedica àquela tarefa e se destaca, tendo esse reconhecimento perdido caso mude de empresa/área de atuação. Por outro lado, o item APS2 "Se deixasse essa organização, sentiria como se estivesse desperdiçando anos de dedicação" foi o menos recorrente para o Entrincheiramento Organizacional na percepção dos funcionários da seguradora, mostrando que eles não considerariam os anos trabalhados como perdidos, caso deixassem a seguradora que trabalham.

Quanto à dimensão da Limitação de Alternativas, pode-se enfatizar o item LA6 "A especificidade do meu conhecimento dificulta minha inserção em outras organizações" (M = 1,94), com isso, o indivíduo verifica a limitação para mudar de área, visto que há anos se dedica ao ramo de seguros e não se sente preparado para concorrer a outras oportunidades em razão do limite de seu conhecimento, e caso venha a mudar de área, terá que começar tudo de novo em termos de conhecimento e aprendizagem, conforme abordado por Rodrigues e Bastos (2012). Enquanto que, na dimensão dos Arranjos Burocráticos Impessoais, o item mais recorrente foi o ABI6 "Se eu fosse trabalhar em outra empresa, deixaria de receber vários benefícios que essa empresa oferece aos seus empregados (vale-transporte, convênios médicos, vale-refeição, etc.)" ( $M=3,06)$, mostrando que o funcionário percebe uma perda significativa caso venha a deixar a organização.

De modo geral, os itens que tiveram menores concordâncias foram: APS2 "Se deixasse essa organização, sentiria como se estivesse desperdiçando anos de dedicação"; LA5 "Meu perfil profissional não favorece minha inserção em outras organizações"; e ABI1 "Sinto que mudar de empresa colocaria em risco a minha estabilidade financeira", e isso possibilita apontar que os funcionários não demonstraram, de forma significativa, a percepção de que perderiam investimentos, a dedicação para o seu reconhecimento e a ideia de que teriam restrições no mercado de trabalho ou falta de alternativas de emprego, caso deixassem a organização na qual trabalham (Rodrigues \& Bastos, 2012).

Na Tabela 4 evidenciam-se as dimensões do Entrincheiramento Organizacional, bem como o Alfa de Cronbach, com valor médio de 0,78, evidenciando a confiabilidade interna dos itens das dimensões. A média geral do EO foi 2,22, o que demonstra um baixo entrincheiramento. Os arranjos burocráticos impessoais obtiveram a maior média $(M=3,00)$, entre as dimensões; em seguida, ajustamentos à posição social $(M=1,93)$ e limitação de alternativas $(M=1,71)$.

Tabela 4

Média e desvio padrão da EEO

\begin{tabular}{lrrrr}
\hline Dimensões & N. de itens & \multicolumn{1}{c}{ Média } & Desvio padrão & Alfa de Cronbach \\
\hline Arranjos Burocráticos Impessoais (ABI) & 6 & 3,0098 & 1,44 & 0,82 \\
Ajustamentos à Posição Social (APS) & 6 & 1,9362 & 1,19 & 0,67 \\
Limitação de Alternativas (LA) & 6 & 1.7156 & 1,09 & 0,87 \\
EEO & 18 & 2,22 & 1,24 & 0,78 \\
\hline
\end{tabular}

Percebe-se a dimensão $A B I$ como principal fator de limitação para a busca por um novo emprego ou nova área de atuação, visto que a perda dos benefícios concedidos pela atual empresa traria um prejuízo financeiro para o funcionário (Rodrigues, 2009; Zacher et al., 2015). Em 
seguida, a dimensão APS elucida que a perda de relacionamento seria o fator que evitaria a saída do colaborador. Na sequência, a dimensão de menor relevância foi a LA, ou seja, os colaboradores não estão preocupados com a perda dos investimentos na área e que tal situação não traria restrição no mercado de trabalho ou falta de alternativas de emprego caso deixassem a instituição (Macambira et al., 2015; Rodrigues \& Bastos, 2012).

\subsection{RELAÇÃO ENTRE OS VALORES NO TRABALHO E O ENTRINCHEIRAMENTO ORGANIZACIONAL}

Com o intuito de responder ao terceiro objetivo específico desta pesquisa "relacionar as dimensões dos valores no trabalho e do Entrincheiramento Organizacional", utilizou-se a análise dos dados por meio da correlação de Pearson (Tabela 5).

Tabela 5

Correlação entre os valores no trabalho e o Entrincheiramento Organizacional

\begin{tabular}{|c|c|c|c|c|c|c|c|}
\hline & & UB & PO & RE & SE & $\mathrm{CO}$ & $\mathrm{AE}$ \\
\hline & Correlação de Pearson & $288^{* *}$ & 184 &, $226^{*}$ & $339^{* *}$ & $299^{* *}$ &, $336^{* *}$ \\
\hline \multirow[t]{3}{*}{ APS } & Sig. (2 extremidades) &, 003 &, 063 &, 023 &, 000 &, 002 & .001 \\
\hline & $\mathrm{N}$ & 102 & 102 & 102 & 102 & 102 & 102 \\
\hline & Correlação de Pearson & 055 &, 126 &, 038 & $485^{* *}$ & , 177 &,- 039 \\
\hline \multirow[t]{3}{*}{ LA } & Sig. (2 extremidades) &, 586 & 206 & ,706 &, 000 &, 076 & 699 \\
\hline & $N$ & 102 & 102 & 102 & 102 & 102 & 102 \\
\hline & Correlação de Pearson & 189 &, 118 &, 001 &, $575^{* *}$ & $230^{*}$ & .090 \\
\hline \multirow[t]{2}{*}{$A B I$} & Sig. (2 extremidades) & 057 & 236 &, 995 &, 000 & ,020 &, 368 \\
\hline & $\mathrm{N}$ & 102 & 102 & 102 & 102 & 102 & 102 \\
\hline
\end{tabular}

Incluem-se duas observações referentes à correlação a respeito da sua significância, que podem ser significantes nos níveis 0,01 e 0,05, representadas na análise da correlação de Pearson, respectivamente, com dois asteriscos e um asterisco, medindo a força da relação entre duas variáveis. De acordo com a avaliação de Bisquerra, Sarriera e Matínez (2009), as variações do coeficiente de Pearson, entre 0,01 e 0,19, são classificadas como associações muito baixas; de 0,20 a 0,39, baixas; de 0,40 a 0,59, moderadas; de 0,60 a 0,79, altas; de 0,80 a 0,99, muito altas; e 1 correlação perfeita.

Verificaram-se que as correlações mais representativas foram Segurança (SE) com Ajustamentos à Posição Social (APS) (correlação baixa =0,339), Limitação de Alternativas (LA) (correlação moderada $=0,485$ ) e Arranjos Burocráticos Impessoais (ABI) (correlação moderada = 0,575), com correlações estatisticamente significantes, possibilitando-se, então, apontar que quanto mais o indivíduo se sente seguro na organização, com sucesso e estabilidade financeira (Porto \& Pilati, 2010; Schwartz et al., 2012; Schwartz, 2017), mais percebe que os investimentos feitos são necessários para a sua adaptação no trabalho, que perderiam vários benefícios caso saíssem da seguradora e que não teriam tantas possiblidades de outros trabalhos, por questões de qualificação 
ou idade, caso também deixassem a segurada na qual trabalha (Carson \& Carson, 1997; Rodrigues, 2009; Rodrigues \& Bastos, 2012; Zacher et al., 2015).

Além disso, Conformidade ( $\mathrm{CO}$ ) apresentou correlações positivas com Ajustamentos à Posição Social (APS) (correlação baixa = 0,299) e Arranjos Burocráticos Impessoais (ABI) (correlação moderada $=0,230$ ), inferindo-se que quanto mais o indivíduo mostra um apreço por aspectos normativos e hierárquicos bem definidos (Porto \& Pilati, 2010; Schwartz et al., 2012), maior a preocupação com o emprego, sentindo-se ainda entrincheirado.

A dimensão Ajustamentos à Posição Social (APS) apresentou relação positiva com Universalismo/benevolência (UB) (correlação baixa =0,288), que se refere a quanto mais o indivíduo se preocupa com as questões sociais e humanitárias (Porto \& Pilati, 2010), maior a percepção de que os investimentos realizados são necessários para a adaptação no trabalho; com Realização (RE) (correlação baixa $=0,226$ ), o reconhecimento pelo seu trabalho no ramo em que está (Porto \& Pilati, 2010; Rodrigues \& Bastos, 2012); e com Autodeterminação/estimulação (AE), com valores ligados à inovação, autonomia, criação e desafios na área (Carson et al., 1995; Rodrigues \& Bastos, 2012; Zacher et al., 2015).

A partir da correlação dos dados, foram encontradas 6 correlações baixas, 10 muito baixas e 2 moderadas, tendo em vista que a dimensão limite Arranjos Burocráticos Impessoais (ABI) foi a que obteve a variação mais próxima do positivo junto aos valores no trabalho. É possível identificar, portanto, como os tipos motivacionais se relacionam com as dimensões de EO, podendo-se apontar:

a) o entrincheiramento como perda de benefícios com a saída, mas a realização atrelada a essa dimensão, ou seja, o reconhecimento pelo seu trabalho no ramo em que está;

b) percepção da perda de investimentos feitos para adaptação e a busca pela sua independência financeira;

c) percepção de restrições de empregabilidade/conteúdo e importância dada à segurança financeira e ao bem-estar em sociedade.

Esses achados revelam que o funcionário não se prende ao fato de estar em harmonia com a sociedade e não se preocupa com a perda dos investimentos já realizados. De modo geral, foram verificadas evidências de uma pouca relação entre os valores no trabalho e o Entrincheiramento Organizacional, visto que a maioria das variações do coeficiente de Pearson apresentou associações muito baixas.

\section{CONSIDERAÇÕES FINAIS}

Nesta pesquisa teve-se como objetivo analisar a relação entre os valores no trabalho e o Entrincheiramento Organizacional, tomando-se como base os funcionários de uma seguradora, dado que a metodologia se mostrou pertinente para atender aos objetivos no estudo. Os resultados apontaram que existe relação entre a percepção da perda de benefícios e a saída do indivíduo 
da seguradora, caso saísse da organização; e segurança e estabilidade financeira que tem na organização. Diante disso, os indivíduos com mais segurança financeira têm mais receio em se desligar da organização.

Em relação ao primeiro objetivo específico, "identificar a hierarquia dos valores relativos ao trabalho", pode-se ressaltar que as principais recompensas desejáveis, por meio do trabalho, são os valores relativos à segurança, em poder se sustentar financeiramente, e a realização em ser bemsucedido na função que exerce. Também foi valorizada a adequação das normas estabelecidas pela empresa e a boa relação entre os colegas da área, gerando um clima organizacional favorável na rotina dos funcionários da organização. Entretanto, os funcionários indicaram como menos relevantes a independência de pensamentos, o status social e a necessidade de viajar pela empresa para mudar o ambiente de trabalho.

No tocante ao segundo objetivo, "verificar o nível de Entrincheiramento Organizacional", obteve-se o principal fator de limitação para buscar um novo emprego à dimensão dos Arranjos Burocráticos Impessoais (ABI), ou seja, a percepção de que sair da instituição provocaria a perda de benefícios. Todavia, as dimensões por Ajustamentos à Posição Social (APS) ou por Limitação de Alternativas (LA) não tiveram grandes relevâncias nas percepções dos funcionários, fato indicativo para inferir que os indivíduos não acreditam que se saíssem da organização estariam, então, desperdiçando os esforços feitos para a sua adaptação social e adequação a novos processos.

Com o terceiro objetivo "relacionar as dimensões dos valores no trabalho e do Entrincheiramento Organizacional", constatou-se, por meio das correlações, que o fato de os indivíduos estarem satisfeitos com a empresa que trabalham é em decorrência do ganho dos benefícios, que os deixam, de certo modo, entrincheirados com o medo da perda financeira, caso saíssem da seguradora na qual trabalham. Então, os indivíduos com mais segurança e estabilidade financeira na empresa se sentem mais entrincheirados do que os demais, sendo esse o valor hierárquico mais relacionado com o Entrincheiramento Organizacional.

Nesta pesquisa buscou-se contribuir academicamente para o entendimento de como os valores no trabalho e o Entrincheiramento Organizacional se relacionam na prática, podendose, a partir disso, propiciar ações, políticas e práticas organizacionais com o intuito de minimizar a desmotivação dos funcionários, evitando o entrincheiramento na organização, e assim alinhar os valores dos indivíduos ao trabalho. Em uma perspectiva gerencial, este estudo serve como um diagnóstico para os gestores, visto que possibilita identificar os principais valores no trabalho e quais são os aspectos do entrincheiramento predominantes na percepção dos funcionários de uma seguradora.

Em futuras pesquisas, sugere-se suplantar algumas limitações que existem nesta investigação, com um maior aprofundamento das análises sobre o perfil profissional dos funcionários das seguradoras de outras cidades brasileiras, bem como com a pesquisa de natureza qualitativa, a fim de investigar os valores no trabalho e o Entrincheiramento Organizacional na perspectiva dos funcionários de seguradoras. 


\section{REFERÊNCIAS}

Almeida, A. A. P., Azevedo, J. Jr., \& Aquino, L. Q. A. (2017). Comprometimento, consentimento e entrincheiramento organizacional: Vínculo entre colaborador e organização. Amazônia: Science \& Health, 5(1), 12-19.

Baiocchi, A. C., \& Magalhães, M. (2004). Relações entre processos de comprometimento, entrincheiramento e motivação vital em carreiras profissionais. Revista Brasileira de Orientação Profissional, 5(1), 63-69.

Becker, H. S. (1960). Notes on the concept of commitment. The American Journal of Sociology, 66 , 32-40.

Bisquerra, R., Sarriera, J. C., \& Matínez, F. (2009). Introdução à estatística: Enfoque informático com o pacote estatístico SPSS. Porto Alegre: Bookman.

Blustein, D. (2013). The psychology of working: A new perspective for career development, counseling, and public policy. Routledge: Abingdon, United Kingdom.

Brandão, R. A., Ferraz, S. B., \& Lima, T. C. B. (2015). Mulheres e Valores do Trabalho: Estudo em uma Multinacional. Revista Organizações em Contexto-online, 11 (22), 487-514.

Bruschini, C. (2000). Gênero e trabalho no Brasil: Novas conquistas ou persistência da discriminação. Trabalho e Gênero: Mudanças, permanências e desafios, 34, 13-58.

Campos, S. A. P., Lehnhart, E. R., Fossá, M. I. T., \& Balsan, L. A. G. (2017). Valores relativos ao trabalho em uma instituição pública de ensino superior. Revista Pretexto, 18(1), 11-27.

Caprara, G. V., Vecchione, M., Schwartz, S. H., Schoen, H., Bain, P. G., Silvester, J., . . Baslevent, C. (2017). Basic values, ideological self-placement, and voting: A cross-cultural study. Cross-Cultural Research, 51 (4), p. 388-411.

Carson, K. D., Carson, P. P., \& Bedeian, A. G. (1995). Development and construct validation of a career entrenchment measure. Journal of Occupational and Organizational Psychology, 68(4), 301-320.

Carson, K. D., Carson, P. P., Roe, C. W., \& Phillips, J. S. (1996). A career entrenchment model: Theoretical development and empirical outcomes. Journal of Career Development, 22 (4), 273-286.

Carson, K. D., \& Carson, P. P. (1997). Career entrenchment: a quiet march toward occupational death? The Academy of Management Executive, 11 (1), 62-75. 
Carvalho, P., Alves F. J. O., Peixoto A. L. A., \& Bastos, A. V. B. (2011). Comprometimento afetivo, de continuação e entrincheiramento organizacional: Estabelecendo limites conceituais e empírico. Psicologia: Teoria e Prática, 13(2).

Cohen, A., \& Shamai, O. (2010). The relationship between individual values, psychological well-being, and organizational commitment among Israeli police officers. Policing: An International Journal of Police Strategies \& Management, 33(1), 30-51.

Cohen, A. Relationships among five forms of commitment: An empirical assessment. (1999). Journal of Organizational Behavior, 285-308.

Collis, J., \& Hussey, R. (2005). Pesquisa em administração: Um guia prático para alunos de graduação e pós-graduação. Porto Alegre: Bookman.

Costa, L. V., \& Dutra, J. (2011). Avaliação da carreira no mundo contemporâneo: Proposta de um modelo de três dimensões. Revista de Carreiras e Pessoas (ReCaPe), 1 (1), p. 1-22.

Dens, N., Pelsmacker, P., \& Meulenaer, S. (2017). Who Do We Help? How Schwartz Values Influence Responses to Different Frames in Charity Appeals. Journal of Marketing Development and Competitiveness, 11 (4), 131-144.

Elizur, D., \& Sagie, A. (1999). Facets of personal values: A structural analysis of life and work values. Applied Psychology, 48(1), 73-87.

Fernandes, H. A., \& Ferreira, M. A. (2009). O impacto dos valores pessoais e organizacionais no comprometimento com a organização. Psico-Usf, 14 (3), 341-353.

Freire, D. A. L. (2015). A Influência da Gestão de Pessoas no Potencial de Crescimento das Micro e Pequenas Empresas (MPEs). Revista Organizações em Contexto, 11 (21), 185-210.

Hair, F., Jr., Black, W. C., Babin, B. J., Anderson, R. E., \& Tatham, R. L. (2009). Análise Multivariada de Dados (A. S. Sant'anna, Trad.). (6 ${ }^{a}$ ed.). Porto Alegre: Bookman.

Macambira, M. O., Bastos, A. V. B., \& Rossoni, L. (2015). Redes sociais e o vínculo com a organização: Como a estrutura das relações explica o comprometimento, o entrincheiramento e o consentimento. Revista Psicologia Organizações e Trabalho, 15(2), 109-122.

Magalhães, M. O., \& Gomes, W. B. (2007). Personalidades vocacionais e processos de carreira na vida adulta. Psicologia em Estudo, 12(1), 95-103.

Maurer, T. J., Hartnell, C. A., \& Lippstreu, M. (2017). A model of leadership motivations, error management culture, leadership capacity, and career success. Journal of Occupational and Organizational Psychology, 90(4), 481-507. 
Meglino, B. M., \& Ravlin, E. C. (1998). Individual values in organizations: Concepts, controversies, and research. Journal of management, $24(3), 351-389$.

Menezes, S. R., Paiva, L. E. B., \& Lima, T. C. B. (2018). Os valores relativos ao trabalho e o entrincheiramento organizacional dos servidores de uma universidade pública. Revista Gestão Universitária na América Latina-GUAL, 11 (3), 166-187.

Merlo, A. R. C., \& Mendes, A. M. B. (2009). Perspectivas do uso da psicodinâmica do trabalho no Brasil: Teoria, pesquisa e ação. Cadernos de Psicologia Social do Trabalho, 12 (2), 141-156.

Nord, W. R., Brief, A. P., Atieh, J. M., \& Doherty, E. M. (1988). Work Values and The Conduct of Organizational-Behavior. Research in organizational behavior, 10, 1-42.

Oliveira, O. M., El-Aouar, W. A., De Vasconcelos, C. R. M., \& Gurgel, F. (2016). Valores relativos ao trabalho em gestores do poder legislativo municipal-Natal, RN. RACE, Revista de Administração, Contabilidade e Economia, 15(2), 705-728.

Paiva, K. C. M., \& Dutra, M. R. S. (2017). Valores Organizacionais e Valores do Trabalho: Um estudo com operadores de call center. Cadernos EBAPE. BR, 15(1), 40-62.

Paiva, L. E. B., Lima, T. C. B., \& Pitombeira, S. S. R. (2017). Percepção de sucesso na carreira de pessoas com deficiência: Um Estudo em Organizações Cearenses. Perspectivas Contemporâneas, $12(2), 35-54$.

Parks-Leduc, L., Feldman, G., \& Bardi, A. (2015). Personality traits and personal values: A meta-analysis. Personality and Social Psychology Review, 19(1), 3-29.

Perez, S. C. (2017). O lugar das mulheres nas famílias, nas políticas sociais e no mercado de trabalho: Tecendo algumas considerações. Sociedade em Debate, 23(1), 110-141.

Porto, B. J., \& Pilati, R. (2010). Escala revisada de valores relativos ao trabalho - EVT-R. Psicologia: Reflexão e crítica, 23(1).

Porto, B. J., \& Tamayo, A. (2008). Estrutura dos valores pessoais: A relação entre valores gerais e laborais. Psicologia: Teoria e Pesquisa, 23(1), 63-70.

Ribeiro, J. G., Filho, \& Honório, L. C. (2014). Comprometimento organizacional: Comparando docentes efetivos e temporários de uma Instituição de Ensino Superior. Revista Organizações em Contexto, 10(20), 173-204.

Rodrigues, A. C. A., \& Bastos, A. V. B. (2012). Entrincheiramento Organizacional: Construção e validação da escala. Psicologia: Reflexão e Crítica, 25(4). 
Rodrigues, A. C. de. (2009). Do comprometimento de continuação ao entrincheiramento organizacional: O percurso de validação da escala e análise da sobreposição entre os construtos (dissertação de Mestrado) Universidade Federal da Bahia, Salvador.

Rokeach, M. (1973). The nature of human values. New York: Free Press.

Rowe, D. E. O., Bastos, A. V. B., \& Pinho, A. P. M. (2011). Comprometimento e entrincheiramento na carreira: Um estudo de suas influências no esforço instrucional do docente do ensino superior. RAC - Revista de Administração Contemporânea, 15(6), 973-992.

Scheible, A. C. F., \& Bastos, A. V. B. (2013). An examination of human resource management practices' influence on Organizational Commitment and Entrenchment. BAR-Brazilian Administration Review, 10(1), 57-76.

Scheible, A. C. F., \& Bastos, A. V. B. (2006). Comprometimento com a carreira: explorando o conceito de entrincheiramento. Trabalho apresentado no Encontro Nacional da Associação Nacional de Pós-graduação e Pesquisa em Administração, Salvador.

Schneider, H. W. (1917). The theory of values. The Journal of Philosophy, Psychology and Scientific Methods, 14(6), 141-154.

Schwartz, S. H. (1994). Are there universal aspects in the structure and contents of human values? Journal of Social Issues, 50(4), 19-45.

Schwartz, S. H., Cieciuch, J., Vecchione, M., Davidov, E., Fischer, R., BEIERLEIN, C., ... Dirilen-Gumus, O. (2012). Refining the theory of basic individual values. Journal of Personality and Social Psychology, 103(4), 663.

Schwartz, S. H. (2017). The refined theory of basic values. In S. Roccas, and L. Sagiv (Ed.), Values and behavior: Taking a cross-cultural perspective (pp. 51-72). Cham, Switzerland: Springer International Publishing.

Schwartz, S. H. (1992). Universals in the content and structure of values: Theoretical advances and empirical tests in 20 countries. Advances in Experimental Social Psychology, 25, 1-65.

Tamayo, A., \& Mendes, A. M., \& Paz, M. G. T. (2000). Inventário de valores organizacionais. Estudos de Psicologia, 5(2), 289-315.

Tamayo, A., \& Porto, B. J. (2003). Escala de valores relativos ao trabalho. Psicologia: Teoria e Pesquisa, 19(2), 145-152. 
Taylor, M. S., \& Giannantonio, C. M. (1993). Forming, adapting, and terminating the employment relationship: A review of the literature from individual, organizational, \& interactionist perspectives. Journal of Management, 19(2), 461-515.

Wilson, M. E., Liddell, D. L., Hirschy, A. S., \& Pasquesi, K. (2016). Professional identity, career commitment, and career entrenchment of midlevel student affairs professionals. Journal of College Student Development, 57(5), p. 557-572.

Zacher, H., Ambiel, R. A. M, \& Noronha, A. P. P. (2015). Career adaptability and career entrenchment. Journal of Vocational Behavior, 88, 164-173.

\section{Como citar este artigo:}

ABNT

FORMIGA, Ana Paula Timbó et al. Valores e Entrincheiramento Organizacional: um estudo em uma seguradora. RACE, Revista de Administração, Contabilidade e Economia, Joaçaba: Ed. Unoesc, v. 17, n. 3, p. 951-974, set./dez. 2018. Disponível em: <http://editora.unoesc.edu.br/index.php/race>. Acesso em: dia/mês/ano.

APA

Formiga, A. P. T., Paiva, E. B. P., Lima, T. C. B. de, \& Serafim, F. de S. F. (2018). Valores e Entrincheiramento Organizacional: Um estudo em uma seguradora. RACE, Revista de Administração, Contabilidade e Economia, 17(3), 951-974. Retirado de http://editora.unoesc.edu.br/index.php/ race 
